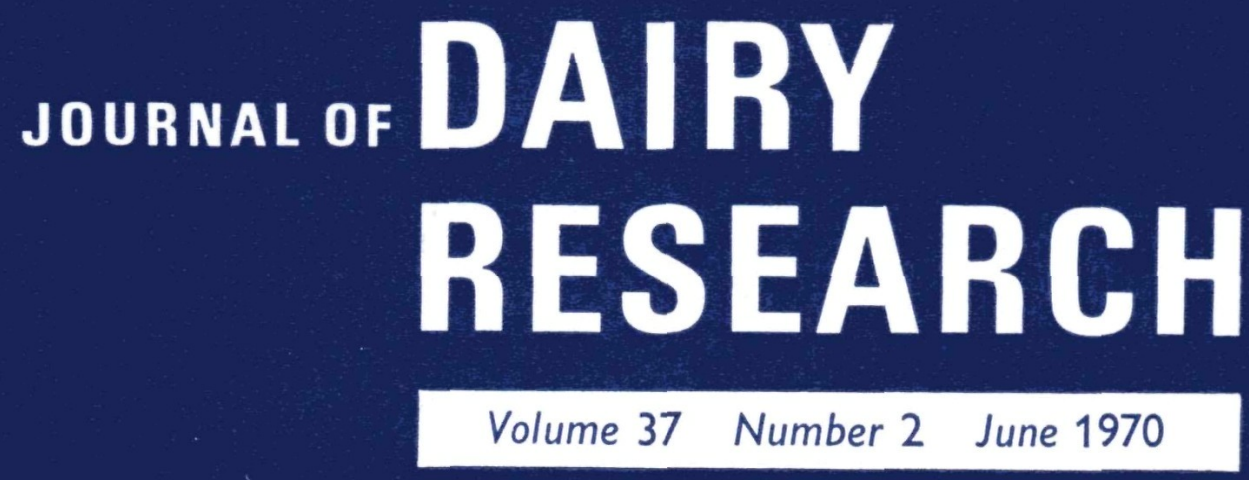




\section{THE JOURNAL OF DAIRY RESEARCH}

was established in 1929 as a medium for the publication of the results of original research in dairy science and cognate subjects. It is published by the Cambridge University Press.

The annual subscription to the Journal is $£ 6$ net (U.S.A. \$20.00) for a volume of three parts. Single copies may be purchased at $50 s$. net (U.S.A. $\$ 8.00$ ) each, plus postage. Subscriptions may be sent to any bookseller or to the Cambridge University Press, Bentley House, 200 Euston Road, London, N.W. 1. Subscribers in the U.S.A. or Canada should send their orders to Cambridge University Press, American Branch, 32 East 57th Street, New York, N.Y. 10022.

Back Volumes. Enquiries about the price and availability of back volumes should be sent to the publishers.

Claims for the replacement of journals believed to have been lost in transmission will only be entertained if made within six months of publication.

\section{Consultative Committee}

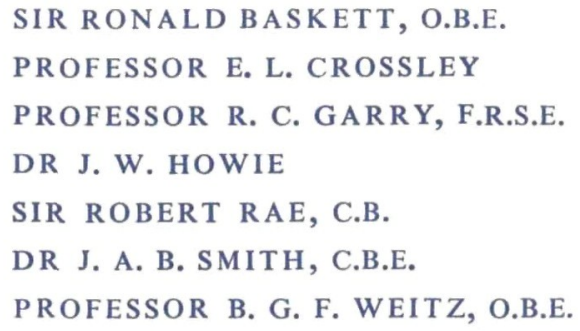

Secretary MR J. C. F. COLES

Editorial Assistant MRS DOROTHY SKIDMORE 


\section{JOURNAL OF DAIRY \\ RESEARCH}

EDITED BY

J. E. FORD, Ph.D.

National Institute for Research in Dairying, Shinfield, Reading, Berkshire

J. A. B. SMITH, C.B.E., Pr.D., D.Sc.

Hannah Dairy Research Institute, Ayr, Scotland

\section{ASSISTED BY}

MR B. F. BONE (Reading)

DR G. C. CHEESEMAN (Reading)

PROF. L. F. L. CLEGG (Canada)

SIR DAVID CUTHBERTSON c.B.E., F.R.s.E. (Glasgow)

DR F. H. DODD (Reading)

DR H. P. DONALD F.R.s.E. (Edinburgh)

PROF. P. J. FOURIE (South Africa)

DR T. GIBSON (Edinburgh)

DR J. O. IRWIN (London)

MR G. LOFTUS HILLS (Australia)

DR L. A. MABBITT (Reading)

DR W. A. McGILLIVRAY (New Zealand)

DR A. ROBERTSON o.B.E., F.R.s. (Edinburgh)

DR K. C. SEN (India)

DR C. C. THIEL (Reading)

DR R. WAITE (Ayr)

DR J. C. D. WHITE (Ayr)

VOLUME 37, 1970 